\title{
Monotonicity and Focus Sensitivity
}

\author{
David I. Beaver and Brady Z. Clark \\ Stanford University
}

\section{Introduction}

Focus sensitive expressions like "always" and "only" can be argued to express quantifier relations with universal force. Thus, like "every", they have a restrictor, and a scope. We take the quantificational domain to be a set of events. Focus sensitivity manifests itself in the fact that (1) and (2) each have multiple readings, two of which may be approximated as (3) and (4). The gloss in (3) is presumably what George Jean Nathan intended in uttering (1), and the focus would thus be "to make others seem more interesting".

(1) I only drink to make others seem more interesting. ${ }^{1}$

(2) I always drink to make others seem more interesting.

(3) Every event of drinking by me has making others seem more interesting as its goal.

(4) Every event with the goal of making others seem more interesting involves me drinking.

Herburger (2000) treats "only" and "always" as event quantifiers and makes the following generalization: "All the nonfocused material in the scope of the event quantifier Q also restricts Q."(Herburger 2000:18)

We argue that data involving negative polarity items (NPIs) bears on the question of which material in a sentence with focus sensitive expressions like "always" and "only" ends up being interpreted in the restrictor. The connection between focus sensitivity and NPI licensing is as follows: both "always" and "only" express forms of universal quantification, and the restrictor of a universal quantifier is standardly recognized as a position licensing a wide range of NPIs. So if Herberger is right, then NPIs should be licensed by both "only" and "always".

On the basis of this argumentation, we will present data in favor of Herberger's analysis as it pertains to "only", but against her analysis in regard to "always". The theoretical importance of this is that it provides reason to believe that focus sensitivity results from two different mechanisms, whereas previous authors appear to have tacitly assumed that a single mechanism can explain all cases of focus sensitivity. We will also seek to clarify issues that have arisen in prior studies of NPI licensing by "only", in particular building on work of Horn (1996) and von Fintel (1999), and will provide a simple formal account which predicts the observed NPI licensing data. 


\section{Polarity item licensing and "only"}

We now present naturally occurring and constructed cross-linguistic data showing that "only" and its cross-linguistic counterparts license NPIs outside of their focus position. This observation (for English) is originally due to Klima (1964). Subsequent discussions of NPI licensing in non-focal positions in the scope of "only" include Herburger (2000:100-104), Horn (1996), Ladusaw (1979), Linebarger (1987), McCawley (1993:83), McCawley (1998:587), von Fintel (1999); cf., Atlas (1993); Atlas (1996).

NPIs have been divided into two main sub-classes (Zwarts 1998; Jackson 1995; Krifka 1995), weak and strong. Weak NPIs in English include unstressed "any" and "ever", "care to" and "bother with". Strong NPIs include such locutions as "lift a finger" and "give a damn/fuck/shit". The NPIs in these classes are differentiated by their distribution: weak NPIs are standardly taken to be licensed in all downward monotone contexts, and (according to Zwarts (1998)) strong NPIs are licensed in a subset of these contexts having the property of anti-additivity. We return to the formal definition of these properties in section 5 .

Horn (1996:8) claims that "only", although an NPI licenser, does not produce an anti-additive context and does not license strong NPIs. The data we will now present shows that "only" licenses both weak and strong NPIs. Our study differs from previous ones in two ways. First, we concentrate on VP modifying "only", studying licensing in non-focal material in the VP. Second, our data is primarily naturally occurring. ${ }^{2}$

Examples (5) - (14) all illustrate NPI distribution in the scope of VP "only". In each case, the relevant occurrence of "only" has been underlined, and the NPI has been boxed. The first four examples illustrate weak NPIs, and the remainder strong NPIs. In all of these cases, the NPI is not the focus of "only".

(5) We only ever had cream of mushroom. ${ }^{3}$

(6) The central problem is that it is only ever possible to sample a child's language over a fixed period of time and within a finite number of situations. ${ }^{4}$

(7) Because we found one order of this group to be much more likely than any other, we probably only care to see the map distances for this single order. ${ }^{5}$

(8) According to his viewpoint, the Miatas are prone to this partly because they don't accumulate miles the way most cars do. The timing belt should be changed at 60,000 miles OR 60 months, and most people only bother with the mileage. ${ }^{6}$

(9) The only words coming out of my mouth is a lyrical thang

So please back tha fuck up off my screen tho

Since i was four you was known to be the enemy

Like rintintin you only give a shit for me

The community took four steps higher

86ing motherfuckas working for the suppliers ${ }^{7}$ 
(10) ... if the left flipper is too weak for a bearkick, as it of ten is because people who run arcades are usually assholes and only give a shit about their street fighter shit games, use that left flipper to send the ball back into the swamp. ${ }^{8}$

(11) Well, I certainly don't give a damn. I only gave a damn because I thought you did. ${ }^{9}$

(12) If you were a kid in Cleveland (then), you only gave a damn about two things - the Beatles and Ghoulardi. ${ }^{10}$

(13) Work is the curse of Stevie Thomas Jackson and Christopher Thomas Geddes. Stuart David, visionary and poet, cursed it before trying it, and would only lift a finger to pick his nose or write a book. ${ }^{11}$

(14) You may think faeries are sweet, good and kind, but they're not. They're vicious, greedy buggers who'd only lift a finger to save their best friend if they thought they'd profit from it. They have sharp teeth too and, as many people have found out, won't hesitate to use them. ${ }^{12}$

We have not collected large amounts of data on NPI licensing of cognates of "only" in languages other than English. However, our initial research on other languages is encouraging. ${ }^{13}$ In Dutch, cognates of "only" also license NPIs. van der Wal (1996) mentions "alleen maar" and "slechts" as members of a class of "inherently negative" expressions which license NPIs. Zwarts (1998:195) classifies phrases of the form "slechts $n \mathrm{~N}$ " and "alleen NP" as monotone decreasing, like their English counterparts "only $n$ N" and "only NP", respectively.

Using web searches, we located several naturally occurring examples of Dutch cognates of "only" licensing NPIs. Note that, with the possible exception (17), these are not VP-modifying uses of cognates of "only".

Negative Polarity Item licensing by "maar": "enig benul"

[Dutch]

Spreker vindt dat het multicultureel erfgoed niet bestaat. Er volgens hem maar één spreker, die enig benul heeft van Vlaamse identiteit... ${ }^{14}$

"Speaker finds that the multi-cultural inheritance does not exist. In his view, [there is] only one speaker who has any notion of the Flemish identity."

Negative Polarity Item licensing by "slechts": "enig benul” [Dutch]

Waarschijnlijk is het altijd al zo geweest dat slechts een kleine minderheid enig benul heeft van de methoden en resultaten van de wetenschap. ${ }^{15}$

"Probably it has always been the case that only a small minority has any notion of the methods and results of science." 
(17) Negative Polarity Item licensing by "alleen": "kan evenaren"

[Dutch]

De motor is wonderlijk sterk en klein. Als we een bacterie opblazen tot de afmetingen van een auto heeft zijn motor een doorsnee van slechts vijf centimeter - een verhouding tussen kracht en afmetingen die onze techniek alleen met gasturbines en raketten kan evenaren. ${ }^{16}$

"The motor is wonderfully strong and small. If we blew up a bacterium to the size of a car, it's motor would only be 5 centimeters across - a power to weight ratio with which in our technology only gas turbines and rockets can compare."

A native Dutch informant reports that the following constructed example in which VP "alleen maar" licenses the NPI "ooit" 'ever' is acceptable:

Negative Polarity Item licensing by "alleen maar": “ooit"

[Dutch]

Jan heeft ooit alleen maar geld aan zijn [moeder $]_{F}$ gegeven.

"Jan only ever gave money to his [mother $]_{F} . "$

We have also found some initial evidence that "nur", the German cognate of "only", licenses NPIs, on the basis of native speaker judgments of the following constructed examples:

(19) Negative Polarity Item licensing by "nur": "einen Muckser von sich gegeben"

[German]

Hans hat nur in dem [haus $]_{\mathrm{F}}$ einen Muckser von sich gegeben.

"Hans only made so much as a peep in the [house]F."

As a last NPI example, we found the following case of "solamente" 'only' licensing an NPI in Spanish:

Negative Polarity Item licensing by "solamente": “dijo una palabra"

[Spanish]

Solamente una lámpara dijo una palabra

y me condujo a salva hasta la habitación ${ }^{17}$

"Only a lamp said a word

And led me in safety up to our quarters" 


\subsection{NPI licensing in the focus of "only"}

The scope of "every" does not license NPIs, so if "only" is akin to a universal as suggested, we would expect that NPIs would not be permitted in the focus position of "only". However, Linebarger (1987) and Horn (1996:27f) provide constructed examples showing that the NPIs "any" and "ever" are licensed in the focus position of "only". The example in (21) is from Linebarger (1987:373).

"Only" licensing NPI "ever" in focal position

Only people who have ever had a debilitating illness themselves can appreciate what an ordeal this was.

Note that (21) is also acceptable without "only" ((22)):

(22) Bare plural licensing NPI "ever" in focal position

People who have ever had a debilitating illness themselves can appreciate what an ordeal this was.

It is easy to find naturally occurring examples of bare plural and definite wh-clauses licensing NPIs to which you can freely add "only".

(23) Definite wh-clause licensing NPI "any"

a. In fact, among the 30.4 million U.S. adults who made any purchase via the Web in the past month, one out of 11 reads PC World. ${ }^{18}$

b. "In fact, among only the 30.4 million U.S. adults who made any purchase via the Web in the past month, one out of 11 reads PC World."

(24) Bare plural licensing NPI "ever"

a. People who had ever been heavy marijuana users cost the nation $\$ 34.2$ billion in diminished worker productivity in $1980 .{ }^{19}$

b. Only people who had ever been heavy marijuana users cost the nation $\$ 34.2$ billion in diminished worker productivity in 1980 .

So Linebarger's (1987) and Horn's (1996) data do not show that "only" licenses weak NPIs in its focus position, merely that independently licensed NPIs may appear there, which is unsurprising. As Horn (1996:28) puts it: "polarity items are possible in this context [the focus position of "only"-DIB/BZC] not because of the semantic properties of only but in spite of them".

Further, note that certain NPs which mark the lowest points on scales are licensed in the focus of "only"; e.g., "She only drank a [drop]F". In such cases "only" has a scalar reading rather than an exhaustive reading. We posit that whenever a phrasal NPI is licensed in the focus of "only", it has a referential interpretation, derived compositionally, putting it on the endpoint of a scale, rather than a purely conventional non-compositional interpretation. For example, "Did Mary have any whiskey?" can be followed by "She only drank [a drop $]_{F}$ !". This reply would only be a true statement if there is some drop of whiskey that Mary drank. Further, it is possible to say "She drank a whole drop!", which exploits the compositional nature of the NPI. 


\section{3. "Always" and polarity item licensing}

Neither corpus searches in the British National Corpus, nor corpus searches in ten years of the New York Times, nor web searches produced any credible examples of the six NPIs from (5) - (14) in positions licensed by an occurrence of "always" (or "usually") in the same clause. ${ }^{20}$ Furthermore, replacement of "only" by "always" in sentences involving NPIs produces infelicity, even after appropriate adjustments have been made. Witness the effects of replacing "only" by "always" in variants of (5) - (14):

(25) People only/*always ever have [cream of mushroom soup $]_{\mathrm{F}} \cdot{ }^{21}$

(26) It is only/*always ever possible to sample a child's language over [a fixed period of time $]_{F}$.

(27) We probably only/?always care to see the map distances for [this single order $]_{F}$.

(28) People only/?always bother with [the mileage $]_{F}$.

(29) People only/?always give a shit for $[\mathrm{me}]_{\mathrm{F}}$.

(30) People only/?always give a shit about [street fighter games] .

(31) I only/?always gave a damn because I thought [you did] $]_{\mathrm{F}}$.

(32) If you were a kid in Cleveland, you only/*always gave a damn about [two things $]_{F}$.

(33) Stuart would only/?always lift a finger to [pick his nose $]_{F}$ or [write a book $]_{F}$.

(34) Faeries would only/?always lift a finger to [save their best friend $]_{\mathrm{F}}$.

Cross-linguistic counterparts of "always" also seem not to license NPIs. Neither van der Wal (1996) nor Zwarts (1998) list any cognates of "always" as NPI licensors in Dutch. Further, while we have found some initial evidence that "nur", the German cognate of "only", licenses NPIs (see example (19)), "immer" 'always' does not, on the basis of native speaker judgments of the example in (35):

Negative Polarity Item licensing by "immer": “einen Muckser von sich gegeben"

[German]

? Hans hat immer in dem [haus] $]_{\mathrm{F}}$ einen Muckser von sich gegeben.

"Hans always made so much as a peep in the [house $]_{\mathrm{F}}$."

Note that NPIs are licensed in adjunct sub-clauses serving as explicit restrictors for "always", as shown in examples (36-38). Although we have not studied the issue of which NPIs are licensed in explicit restrictors of "always", it is clear that there is a disparity between licensing of NPIs in this position, and licensing of NPIs within non-focused material within the main clause. 
(37) They have always been great for customer service and if there is ever a problem they always make you the winner. ${ }^{23}$

If we care to listen, we can always hear them. ${ }^{24}$

\section{PPI licensing}

It is natural to ask whether the distribution of positive polarity items (PPIs; e.g., "rather", "pretty", "quite") differs between "only" and "always". The parallel with "every" would lead to the negative prediction that PPIs should not be licensed in the scope of "only" and "always" outside of the focus. However, as the following examples show, once again there is a contrast between "only" and "always": PPIs are licensed in non-focal positions in the scope of "always", but not "only".

\section{Positive Polarity Item}

a. Mary's ?only/always rather tired on [Sunday $]_{F}$.

b. Mary's ?only/always pretty (damn) tired on [Sunday $]_{\mathrm{F}}$.

Corpus searches for PPIs have not been revealing. However, (40) is an example which is ambiguous as to whether the PPI "quite" occurs in the focus of "always" or not. The fact that the phrase "always been quite useful" can be read without stress provides some further support for our claim that PPIs are licensed in non-focal positions in the scope of "always". We have found no such examples involving "only".

\section{PPI "quite" licensed by "always"}

Traditional economics has always been quite useful for understanding the market forces that shaped industries and governed competition among firms during the first and second revolutions. ${ }^{25}$

\section{Monotonicity Inferences}

The notion of monotonicity relates to inferential properties of parts of sentences. Material that can be arbitrarily strengthened while maintaining truth of the sentence is said to occur in a downward monotone position. We will be presenting our account of the semantics of "only" and "always" in terms of a simple logic, and for this system it is natural to understand downward monotonicity in terms of substitution of sub-formulae. If $\alpha$ is a sub-formula of $\phi$, then we write the result of replacing $\alpha$ with the conjunction of $\alpha$ and $\beta$ as $\phi[\alpha / \alpha \wedge \beta]$, producing the following definition: 
Definition 1 (Test for (simple) downward monotonicity) The expression $\alpha$ occurs in a simply downward monotone position in a sentence $\phi$ iff for any $\beta$ which is stronger than $\alpha$, $\phi$ entails $\phi[\alpha / \beta]$. If $\alpha$ is a set denoting term, then a stronger term would be a narrower one, i.e. one denoting a subset. If $\alpha$ is a proposition, then strength means logical strength, so $\beta$ ranges over expressions that entail $\alpha$, e.g. a conjunction containing $\alpha$ as one conjunct.

It is widely accepted that downward monotonicity is a necessary condition for licensing of NPIs (Fauconnier 1975; Ladusaw 1979), although see Giannakidou (1998) for an alternative view. Similarly, upward monotonicity, i.e. the validity of inferences involving weakening, is widely held to be a necessary condition for licensing of positive polarity items.

Definition 2 (Test for upward monotonicity) The expression $\alpha$ occurs in an upward monotone position in a sentence $\phi$ iff for any $\beta$ which is weaker than $\alpha, \phi$ entails $\phi[\alpha / \beta]$.

Universal quantifier relations have a downward monotonic argument, the restrictor, and an upward monotonic argument, the scope. As a result, Negative Polarity Items (NPIs) are licensed in the restrictor but not the scope. The example in (41) shows licensing of the NPI "ever":

(41) a. Every bear that ever there was is going to be down in the woods because.... ${ }^{26}$

b. * Every bear is ever going to be down in the woods.

As stated in the introduction, we take "only" to express a universal, following argumentation of Horn (1996), who himself cites medieval authority for his position. On Horn's account "Only As are Bs" is logically equivalent to "All Bs are As". Since "All Bs are As" is downward monotone in the B position, "Only As are Bs" should be downward monotone in the B position. Assuming a uniform semantics for NP and VP "only", non-focal material in the syntactic scope of VP "only" should also license NPIs. This is in complete agreement with the data we presented above.

Is the data from NPI licensing backed up by inference tests based on definition 1? Unfortunately, the answer is no. In the following example, the diagnostic for downward monotonicity fails, since the validity of the argument from (42a) to the strengthened $(42 b)$ is dubious.

a. Only Nathan drank to make others seem more interesting. [ $\rightarrow$ ?]

b. Only Nathan drank mojitos to make others seem more interesting.

Von Fintel, as well as presenting an example like (42) showing failure of the monotonicity inference for NP "only", also notes that strengthening non-focal material in the scope of VP "only" is not clearly truth preserving. Thus, for example, it is not clear that (43b) can be inferred from (43a). 
(43) a. Nathan only drank [to make others seem more interesting $]_{\mathrm{F} .}[\rightarrow$ ?]

b. Nathan only drank mojitos [to make others seem more interesting]F.

More generally, it has been observed by Ladusaw (1979) and others (see e.g., Linebarger (1987)) that NPIs are licensed in many cases where strengthening inferences do not appear to hold. Apart from "only", examples of constructions which license NPIs but do not cleanly support monotonicity inferences include emotive factives, superlatives and embedded questions.

von Fintel (1999) discusses a variant of downward monotonicity which is a better predictor of NPI licensing. In partial adoption of von Fintel's terminology, we term this Strawson downward monotonicity. We arrive at the following diagnostic:

Definition 3 (Test for Strawson downward monotonicity) Let presupposition( $\psi$ ) be the strongest sentence presupposed by $\psi$. The expression $\alpha$ occurs in a Strawson downward monotone position in a sentence $\phi$ iff for any $\beta$ which is stronger than $\alpha$, the combination of $\phi$ and presupposition $(\phi[\alpha / \beta])$ entails $\phi[\alpha / \beta]$.

The idea is that "only Nathan drank to make others seem more interesting" entails "only Nathan drank mojitos to make others seem more interesting", under the assumption that the presuppositions of the second are satisfied.

On the analysis we will follow, that of Horn (1996), the presuppositions connected with "only" are existential, i.e. in this case the presupposition is that someone drank mojitos to make others seem more interesting. Note that strengthening the presupposition to "Nathan drank mojitos to make others seem more interesting", in accord with Horn (1969), would not affect our account, although as Horn (1996) clearly shows, it is less motivated.

With the von Fintel inspired revision of the downward monotonicity diagnostic, we can show for NP and VP "only" that downward monotonicity inferences are valid. From (44/45a,b), we can infer (44/45c).

\section{Downward monotonicity: “only NP”,}

a. Someone drank mojitos to make others seem more interesting.

b. Only Nathan drank to make others seem more interesting. $[\rightarrow]$

c. Only Nathan drank mojitos to make others seem more interesting.

\section{Downward monotonicity: "only VP"}

a. Nathan drank mojitos (for some reason).

b. Nathan only drank [to make others seem more interesting] $]_{F}[\rightarrow]$

c. Nathan only drank mojitos [to make others seem more interesting]F.

A function is anti-additive iff it is downward monotonic and when the function holds of two sets, it also holds of their union. For example, take the function from properties " $\mathrm{X}$ " to "No X is 300 years old". From the conjunction of "No woman is 300 years old" and "No man is 300 years old", we can infer "No man or woman is 300 years old". 
Definition 4 (Test for (simple) anti-additivity) The expression $\alpha$ occurs in an anti-additive position in a sentence $\phi$ iff $\phi$ and $\phi[\alpha / \beta]$ are together equivalent to $\phi[\alpha / \alpha \text { or } \beta]^{27}$

It is easily seen that the restrictor of "every" is anti-additive. Not only does the inference from (46b) to (46a) go through (downward monotonicity), but also the inference from (46a) to (46b) is valid. (Here $\alpha$ is "girl", $\beta$ is "boy".) For an example of a non-anti-additive context, consider the the restrictor of "less than three": note that there is a valid (downward monotonicity) inference from (46d) to (46c), but not vice versa.

Anti-Additivity: "every" and "less"

a. Every girl is happy and every boy is happy. $[\leftrightarrow]$

b. Every girl or boy is happy.

c. Less than three girls are happy and less than three boys are happy. [ $\not>]$

d. Less than three boys or girls are happy.

Horn (1996:8) claims that "Only NP", although a polarity licenser, is a nonanti-additive quantifier. If "only" is semantically equivalent to a universal, as Horn argues at length, and if universal restrictors are anti-addititive, then Horn is incorrect to say that non-focal material in the scope of "only" occurs in a non-anti-additive context. But perhaps part of the problem is that presupposition complicates the data we obtain using the standard inference test for anti-additivity.

As with the the superset inference test for downward entailment, a sentence "Only Nathan drank mojitos and only Nathan drank Cajun martinis" is equivalent to "Only Nathan drank mojitos or Cajun martinis" only if all presuppositions are satisfied. Accordingly, we modify the definition of anti-additivity:

Definition 5 (Test for Strawson anti-additivity) The expression $\alpha$ occurs in an anti-additive position in a sentence $\phi$ iff $\phi$ and $\phi[\alpha / \beta]$ are together equivalent to the combination of $\phi[\alpha / \alpha$ or $\beta]$, the presuppositions of $\phi$ and the presuppositions of $\phi[\alpha / \beta]$.

Note that for cases that occur to us, if the presuppositions of $\phi$ and those of $\phi[\alpha / \beta]$ are satisfied, then the presuppositions of $\phi[\alpha / \alpha$ or $\beta]$ will also be satisfied. So it is not necessary to add presuppositions to the lefthand-side of the bi-implication in the above definition.

There is a bi-implication between (a,b) and (c,d,e) in each of (47) and (48), showing that both NP and VP "only" produce Strawson anti-additive contexts outside of their foci. Note that this result corroborates the analysis of "only" as a universal quantifier. ${ }^{28}$

\section{Strawson anti-additivity: “only NP”}

a. Only Nathan drank to make others seem more interesting, and 

b. only Nathan smoked to make others seem more interesting. [ $\leftrightarrow$ ]
c. Only Nathan drank or smoked to make others seem more interesting,
d. someone drank to make others seem more interesting and
e. someone smoked to make others seem more interesting.

\section{Strawson anti-additivity: "only VP"}

a. Nathan only drank [to make others seem more interesting $]_{F}$, and

b. Nathan only smoked [to make others seem more interesting] $]_{F}[\leftrightarrow]$

c. Nathan only drank or smoked [to make others seem more interesting]

d. Nathan drank and

e. Nathan smoked.

The combination of NPI licensing data and inference test data allows us to refute some analyses of "only" which do not account for presuppositions adequately. For example, the cross-categorial analysis of "only" presented by Bonomi and Casalegno (1993) incorporates as a principal part of the meaning of "only" what we (and Horn) give as an existential presupposition. In Bonomi and Casalegno's (1993) event framework "Sandy only eats [nuts] $]_{\mathrm{F}}$ " has a meaning ( $\exists$ eeating $(e) \wedge$ $\operatorname{AGENT}(e)=$ sandy $\wedge \operatorname{THEME}=$ nuts $) \wedge(\forall e$ eating $(e) \wedge \operatorname{AGENT}(e)=\operatorname{sandy} \rightarrow$ THEME $=$ nuts). That analysis predicts that non-focussed material in the scope of NP and VP only is in a non-monotone context, neither upward monotonic nor simply downward monotonic nor Strawson downward monotonic. This is incompatible with either the NPI data presented earlier, or the inference test data presented in this section. ${ }^{29}$

To end this section, let us consider monotonicity inferences involving "always". Our observation here is that monotonicity inferences involving "always" are far less clear than those involving "only", having a will o' the wisp character. In some cases, it seems clear that "always" creates a Strawson downward monotonic context in non-focal material:
a. Nathan sometimes drank mojitos,
b. Nathan always drank [to make others seem more interesting] $]_{\mathrm{F} .}[\rightarrow]$
c. Nathan always drank mojitos [to make others seem more interesting] .

However, consider the contrast between (50) and (51). Whereas the monotonicity inference in (50) is clear, there is no clear inference from $(51 \mathrm{a}, \mathrm{b})$ to $(51 \mathrm{c})$. On the contrary, it seems possible to infer (51b) from (51c), indicating an upward monotonic context.

(50) a. Kids care deeply about something these days.

b. Kids only care about $[\text { music }]_{F}$ these days. $[\rightarrow]$ 
c. Kids only care deeply about [music $]_{F}$ these days.

a. Kids care deeply about something these days.

b. Kids always care about [music $]_{\mathrm{F}}$ these days.[ $\rightarrow$ ?]

c. Kids always care deeply about [music $]_{F}$ these days.

Perhaps the explanation of this puzzling result is that stress in $(51 \mathrm{~b}, \mathrm{c})$ is taken to mark broad focus on "care (deeply) about music", in which case we would be observing inferences involving focal material. But it is not clear why this should not also be the case for the parallel sentences involving "only" in (50), and we have no basis for claiming that focus projection in the scope of "only" should work differently from focus projection in the scope of "always". On the basis of the NPI licensing data we presented earlier, we take a different tack.

We suppose that while compositional semantics causes non-focal material in the scope of NP or VP "only" to be interpreted in the restrictor of a universal, the mechanism determining the restrictor of "always" (when that restrictor is not explicit) is pragmatic. Thus non-focal material in a sentence containing "always" is not interpreted in the restrictor of a universal. Rather, this material gets interpreted in the universal's scope, and NPIs are not licensed there since it is not a (Strawson) downward monotone context. Indeed, it is upward monotone. The variability of inference data involving sentences with "always" would then be explained by the fact that the formation of the restrictor of "always" does not result from an orderly grammatical process, but from pragmatic reasoning.

\section{A Formal Account}

In this section we describe our proposal for the semantics of "only" and "always", show formally how "only" and "always" differ in terms of downward monotonicity and anti-additivity, and hence account for the polarity item licensing behavior that we have observed.

We use a three-valued logic, first order predicate logic with the addition of one propositional operator, the presupposition operator $\partial$ of (Beaver 2001) ${ }^{30}$ The existential and universal quantifiers have classical satisfaction conditions and, for simplicity, $\exists \varphi$ and $\forall \varphi$ are false if not true. The connectives are Weak Kleene; i.e., defined iff all arguments are defined, and classical in this case. The presupposition operator produces undefinedness when its argument is not true, and is defined as follows:

Definition 6 (Presupposition operator) $\llbracket \partial \phi \rrbracket_{M}=1$ iff $\llbracket \phi \rrbracket_{M}=1,=*$ otherwise.

We next give a logical reformulation of the downward monotonicity diagnostics.

Definition 7 (Simple downward monotonicity) A formula $\alpha$ occurs in a simply downward monotone position in $\phi$ iff for any $\beta$ such that $\beta \models \alpha, \phi \models \phi[\alpha / \beta]$. 
Thus, for example, the subformula bark(fido) is in a simply downward monotone position in $\neg$ bark (fido), since classically $\neg$ bark $($ fido $) \models \neg(\operatorname{bark}($ fido $) \wedge$ $\phi)$ for any $\phi$.

The following presupposition sensitive notion of entailment differs from classical entailment in that it is restricted to models in which both premises and conclusion are defined, i.e. their presuppositions are satisfied:

Definition 8 (Strawson Entailment) $\phi_{1}, \ldots \phi_{i} \Vdash \psi$ iff $\forall M$ if $\llbracket \phi_{1} \rrbracket_{M}=\ldots=\llbracket \phi_{i} \rrbracket_{M}=1$ and $\llbracket \psi \rrbracket_{M} \in\{0,1\}$ then $\llbracket \psi \rrbracket_{M}=1$

Relative to this presupposition sensitive notion of entailment, we can easily define what it means to be in a Strawson downward monotonic position or Strawson anti-additive position.

Definition 9 (Strawson downward monotonicity) A formula $\alpha$ occurs in a Strawson downward monotone position in $\phi$ iff for any $\beta$ such that $\beta \Vdash \alpha, \phi \Vdash \phi[\alpha / \beta]$.

Definition 10 (Strawson anti-additivity) A formula $\alpha$ occurs in a Strawson antiadditive position in $\phi$ iff $\alpha$ is in a Strawson downward monotone position in $\phi$ and for any $\beta, \phi \wedge \phi[\alpha / \beta] \Vdash \phi[\alpha / \alpha \vee \beta]$.

We now proceed to the semantics of "only" and "always". We define the semantics of these two operators as uniformly as possible, so as to highlight relevant differences. We assume both words to be universal quantifier relations defined between sets of events, and both words to carry a presupposition that the quantificational restrictor is a non-empty set. A presuppositional universal quantifier relation may be defined in our partial logic as follows:

\section{Definition 11 (Presuppositional universal operator)} $\forall(\phi, \psi) \equiv_{\text {def }} \partial(\exists e \phi) \wedge \forall e(\phi \rightarrow \psi)$.

Now let SUB be the content of the subject NP in a sentence, NF be the content of the non-focal material in the VP, and $\mathbf{F}$ be the content of the focal material in the VP. Then the interpretation of a sentence containing VP "only" is given as follows:

Definition 12 (Semantics of "only")

"NP only VP" translates to $\forall(S U B \wedge N F)(F)$

For example, in the sentence "Mary only has a [lamb $]_{F}$ ", the variables would be set as follows: SUB is AGENT(e)=m; NF is POSSESSION(e); F is $\exists \mathbf{x}(\operatorname{lamb}(\mathbf{x}) \wedge$ $\operatorname{THEME}(e)=x)$. Thus the meaning of the sentence would be (52).

$$
\forall(\operatorname{AGENT}(\mathrm{e})=\mathrm{m} \wedge \operatorname{POSSESSION}(\mathrm{e}))(\exists \mathrm{x}(\operatorname{lamb}(\mathrm{x}) \wedge \operatorname{THEME}(\mathrm{e})=\mathrm{x}))
$$


This formula presupposes that there is some event possession by Mary, and asserts that every such event is one in which the object possessed is a lamb.

One crucial difference between "only" and "always" explains the polarity licensing contrasts we have presented. Whereas the restrictor of "only" is constrained by non-focal material, the restrictor of "always", in the absence of an explicit restrictive subordinate clause, is provided by context. Let $\sigma$ be a contextually given property of events. Then we interpret sentences containing "always" as follows:

\section{Definition 13 (Semantics of "always")}

"NP always VP" translates to $\forall(\sigma)(S U B \wedge N F \wedge F)$

Thus the compositionally derived meaning of "Mary always has a [lamb $]_{\mathrm{F}}$ " would be (53).

$$
\forall(\sigma)(\operatorname{AGENT}(\mathrm{e})=\mathrm{m} \wedge \operatorname{POSSESSION}(\mathrm{e}) \wedge \exists \mathrm{x}(\operatorname{lamb}(\mathrm{x}) \wedge \operatorname{THEME}(\mathrm{e})=\mathrm{x}))
$$

Questions arise as to how $\sigma$ should be resolved, and how its resolution should be related to focus. Here we do not answer these questions, and merely make the claim that $\sigma$ is resolved pragmatically, and not compositionally.

Note that the above meanings for "only" and "always" differ not only in the restrictor position, but also in the scope, i.e. the second argument of the universal operator. However, this difference is superficial. Since $\forall($ SUB $\wedge N F)(F) \equiv$ $\forall(S U B \wedge N F)(S U B \wedge N F \wedge F)$, we could equally well have written out the meanings for "only" and "always" such that the scope of the quantifier was the same in both cases, i.e. SUB $\wedge \mathrm{NF} \wedge \mathrm{F}$.

Let us assume that weak NPIs are licensed in Strawson downward monotone positions and strong NPIs are licensed in Strawson anti-additive positions. The following easily proven fact is now derivable from the above definitions and predicts the NPI licensing data presented earlier.

FACT NF is in a Strawson Downward Entailing and Strawson Anti-additive position in the translation of "NP only VP", but NF is not in a Strawson Downward Entailing or (a fortiori) in a Strawson Anti-additive position in the translation of "NP always VP".

\section{Discussion}

The monotonicity data we have examined in this paper supports the hypothesis that non-focal material in the scope of "only" is interpreted in the restrictor of a universal. Concerning "always", the data discussed so far is puzzling. Standard examples of focus sensitivity show that there is a correlation between unfocussed material and the adverb's semantic restrictor. Yet we have presented evidence that in simple sentences involving "always", unfocussed material is not interpreted in the restrictor of a universal. 
In other work (Beaver and Clark submitted; Beaver and Clark 2002; Beaver and Clark in prep), we discuss a range of phenomena which support the analysis we have given. One of these phenomena is a converse effect to the one we have concentrated on here: whereas stressed material in the scope of "only" becomes the semantic focus of the operator, sometimes "always" does not associate with stressed material in its scope. Rather, the restrictor of "always" is determined contextually, often producing an effect that has been described, e.g. by Rooth (1999), as association with presupposition; for the original observation, see Schubert and Pelletier (1987); Schubert and Pelletier (1989). We conclude with an example showing the effect for "always", and the absence of the effect for "only".

The example, (54), is drawn from a British newspaper, and concerns the sport of rugby. Various readings are available. It is possible to understand the subject "a prop forward" as the semantic focus of "always". What is notable is that this reading is obtained even if the example is read with stress on "brunt" and "punishment", but not on "prop forward". Here, what is presupposed is a set of high-speed collisions, from which punishment will necessarily follow, and from which some group of players will bear the brunt. Against this background, we learn the identity of the unfortunate recipients of the punishment, namely the prop forwards.

(54) It's a high-speed collision sport and a prop forward always takes the brunt of the punishment. ${ }^{31}$

A reading of this sort is not available in (55). The reading that we obtain, with stress on "brunt" and "punishment", is that a prop forward does not take the brunt of anything apart from the punishment. This is presumably true, but we are not sure what it means.

A prop forward only takes the [brunt of the punishment $]_{\mathrm{F}}$.

\section{Endnotes}

${ }^{1}$ George Jean Nathan, below his picture in Charley O's, 214 W. $45^{\text {th }}$ St., New York City.

${ }^{2}$ Some possible counterexamples to the licensing of strong NPIs by "only" are given by Atlas (1996) (and also in recent unpublished work), involving the NPIs "until", "all that keen" and "a red cent". Regarding "a red cent", we find it difficult to find reliable informants. But regarding "until" and "all that keen", we are in agreement with Atlas' jugements. Note also that these items are licensed in canonical negative contexts, as in "Nobody left until Sunday" or "Nobody was all that keen to leave". Crucially, however, these items do not sit well in the restrictor of "every". For example "Everybody that left until Sunday returned" is quite odd, as is "Everybody that was all that keen to leave returned". We conclude that the licensing conditions for these operators must go beyond those available in the restrictor of a universal, 
and thus that these items perhaps form part of a distinct class of NPIs with their own licensing properties. Whatever the licensing conditions of "until" and "all that keen", it seems unlikely that they can provide evidence either for or against our claims about "only".

${ }^{3}$ Muriel Gray, The first fifty, Mainstream Publishing, Edinburgh, 1990.

${ }^{4}$ John Harris, Early language development, Routledge and Kegan Paul, London, 1990.

${ }^{5}$ Stephen Lincoln, Mark Daly and Eric Lander, Constructing Genetic Linkage Maps with MAPMAKER/EXP Version 3.0: A Tutorial and Reference Manual, Whitehead Institute for Biomedical Research Technical Report, January, 1993.

${ }^{6}$ http: / / www. socalm.org/crank/crank199609.pt1.html — archived email.

${ }^{7}$ The Coup, "Interrogation", on Genocide and Juice, Wild Pitch/EMI Records, 1994 (CD).

${ }^{8}$ http://www.acc.umu.se/ oscar/pinball/gbook/guestbook.html-A page for pinball lovers.

${ }^{9}$ Jamie Malankowski, "Five Finales: How to wrap up Seinfeld? We offer some suggestions", Time Magazine 151:17, May 4 1998. Note: we take it that in this example the focus of "only" is the "because" clause although "gave" would also be read with contrastive stress to mark the past tense morpheme.

${ }^{10}$ Mike Olszewski, quoted in the Akron Beacon Journal, October 9, 1998.

${ }^{11}$ Belle and Sebastian, If You're Feeling Sinister (CD Sleeve Notes), Jeepster 1996.

${ }^{12}$ Online text at http://www . angel fire.com/me/Spero/folks.html .

${ }^{13}$ An exception is Hebrew, for which in initial work we found no evidence of "rak" ("only") licensing NPIs. The languages for which we have positive data are all Romance or Germanic.

${ }^{14} \mathrm{De}$ heer Raets, quoted in the minutes of the meeting of the Provincieraad van Antwerpen, October 1998.

${ }^{15}$ Maarten van Rossem, Geloof en Wetenschap, September 1999. Note first that "minderheid" ("minority") could also be the relevant NPI licensor. Second, there is an occurrence of "altijd" ("always") in the first clause. However, the NPI falls clearly in the semantic scope of "altijd", not its restrictor, so this is presumably irrelevant.

16“"Bouwen in een kleine wereld", KIJK.

17 Benjamín Valdivia, "Sobre un afortunado papel de fotografía", in El Juego del Tiempo. Secretaría de Educación Pública / CREA Mexico, 1985.

18 http://marketing.pcworld.com/site/pressreleases/fall2001mri.html

${ }^{19} \mathrm{Ed}$ Falk, Lies in the war on drugs, repost from misc.activism.progressive, $1 / 25 / 1993$.

${ }^{20}$ However, we do find examples of "any" and its variants ("anything", etc.) in VPs modified by "always". It seems that we are forced to regard "any" as exceptional. This, of course, is not an unusual move. There is a large literature attempting to explain the distribution facts of "any", much of which simply assumes that "any" is ambiguous between NPI and so-called free-choice readings - see Kadmon and Landman (1993) and Krifka (1995) for attempts to do without this ambiguity.

${ }^{21}$ The impossibility of "always" and "ever" in (25) could result from a mismatch 
between the temporal interpretations of "always" and "ever", and have nothing to do with polarity per se. However, "never ever" is felicitous, suggesting that the issue is one of monotonicity not temporality. Note also that there are positive uses of "ever", meaning roughly "forever": these are common in the scope of "always", generally as a form of emphasis. Ideally a diagnostic should be developed to separate positive and negative uses of "ever".

${ }^{22}$ Joe Greenwood, "Eye of the Storm: Taking It Easy", AIDS Survival Project: A coalition of people affected by HIV, Atlanta, 1999.

${ }^{23}$ P.M., Miami, Florida, as recorded on the Arts and Letters Corporation web pages. ${ }^{24}$ W.H. Auden, In Time of War: Commentary.

${ }^{25}$ David Evans and Matthew Leder, "Economics for the Third Industrial Revolution”, Viewpoint 1, Marsh and McLennan Companies, 1999.

${ }^{26}$ James B. Kennedy, The Teddy Bear's Picnic, 1913. (Tune composed John W. Bratton, 1907, presumably inspiring use of an NPI.)

${ }^{27}$ Note that the leftward direction of this bi-implication is equivalent to downward monotonicity, since $\alpha$ is just a strengthening of $\alpha$ or $\beta$, and so is $\beta$.

${ }^{28}$ Note that Atlas (1996) argues that "only Count Noun" is a downward monotonic, anti-additive quantifier expression, while "only Proper Name" is a non-monotonic, pseudo-anti-additive quantifier expression. We would claim that neither "only Count Noun" nor "only Proper Name" are simply downward monotonic, and, a fortiori, neither are simply anti-additivity. We would also claim that both are Strawson antiadditive and, a fortiori, both are Strawson downward monotonic.

${ }^{29}$ The question arises as to whether "every" creates an anti-additive context, or merely a Strawson anti-additive context. Note that many people would be queasy about the equivalence of "Every American head of state has been male." and "Every American president has been male and every American monarch has been male.", even under the assumption that all heads of state are either presidents or monarchs. So perhaps we should say that "every", like "only", creates a Strawson anti-additive context.

${ }^{30} \mathrm{We}$ treat presupposition in a partial logic because of the formal simplicity of this approach, although nothing hinges on it. For a compositional account of presupposition in partial logic, see Beaver and Krahmer (2001).

${ }^{31}$ The Daily Mirror, Mirror Group Newspapers, London 1992.

\section{References}

ATLAS, JAY. 1993. The Importance of Being "Only": Testing the Neo-Gricean Versus Neo-entailment Paradigms. Journal of Semantics 10.301-318.

— 1996. 'Only' Noun Phrases, Pseudo-Negative Generalized Quantifiers, Negative Polarity Items, and Monotonicity. Journal of Semantics 13.265-328.

BeAver, DAVID. 2001. Presupposition and Assertion in Dynamic Semantics. CSLI Publications. 
—, and BRADY ClARK. 2002. The Proper Treatments of Focus Sensitivity. In Proceedings of WCCFL 21, Somerville, Mass. Cascadilla Press.

— and - in prep. Focus Sensitivity. Stanford University, ms.

- and - - submitted. "Always" and "Only": Why not all Focus Sensitive Operators are Alike. Stanford University, URL: http://www.stanford.edu/ dib/paper.htm, ms.

- , and EMIEL KRAHMER. 2001. A partial account of presupposition projection. Journal of Logic, Language and Information 10.147-182.

Bonomi, Andrea, and PaOlo Casalegno. 1993. Only: Association with Focus in Event Semantics. Natural Language Semantics 2.1-45.

FAUCONNIER, GiLES. 1975. Polarity and the scale principle. In Chicago Linguistics Society, volume 11, 188-199.

GiAnNAKIDOU, ANASTASIA. 1998. Polarity sensitivity as (non)veridical dependency. Amsterdam/Philadelphia: Linguistik Aktuell (Linguistics Today), John Benjamins.

Herb URGer, ElenA. 2000. What Counts: Focus and Quantification. MIT Press.

HORN, LAURENCE. 1969. A presuppositional analysis of only and even. In Papers from the Fifth Regional Meeting of the Chicago Linguistics Society, 98-107.

- 1996. Exclusive Company: Only and the Dynamics of Vertical Inference. Journal of Semantics 13.1-40.

JACKSON, ERIC. 1995. Weak and Strong Polarity Items: Licensing and Intervention. Linguistic Analysis 25.181-208.

KADMON, NiRIT, and FRED LANDMAN. 1993. Any. Linguistics and Philosophy $16.353-422$.

KLIMA, EDWARD. 1964. Negation in English. In The Structure of Language, ed. by Jerry A. Fodor and J.J. Katz, 246-323. Prentice-Hall.

KrifKA, MANFRED. 1995. The Semantics and Pragmatics of Polarity Items. Linguistic Analysis 25.1-49.

LaduSaW, William. 1979. Polarity Sensitivity as Inherent Scope Relations. University of Texas at Austin dissertation.

LiNEBARGER, MARCIA C. 1987. Negative Polarity and Grammatical Representation. Linguistics and Philosophy 10.325-387.

MCCAWley, JameS D. 1993. Everything that Linguists Have Always Wanted to Know about Logic but Were Ashamed to Ask (Second Edition). Chicago: University of Chicago Press. 
1998. The Syntactic Phenomena of English (Second Edition). Chicago: University of Chicago Press.

RoOTH, MATS. 1999. Association with Focus or Association with Presupposition? In Focus: Linguistic, Cognitive and Computational Perspectives, ed. by Peter Bosch and Rob van der Sandt, 232-244. Cambridge University Press.

Schubert, Lenhart K., and Francis JeFFry PElletier. 1987. Problems in the representation of the logical form of generics, plurals, and mass nouns. In New Directions in Semantics, ed. by E. LePore, 385-451. Academic Press.

— , and —. 1989. Generically Speaking, Or Using Discourse Representation Theory to Interpret Generics. In Properties, Types and Meaning, ed. by Gennaro Chierchia, Barbara H. Partee, and Raymond Turner, volume II, 193-268. Kluwer Academic Publishers.

VAN DER WAL, SJOUKJE. 1996. Negative Polarity Items and Negation: Tandem Acquisition. University of Groningen dissertation.

VON FINTEL, KAI. 1999. NPI Licensing, Strawson Entailment. Journal of Semantics 16.97-148.

ZWARTS, FRANS. 1998. Three types of polarity. In Plurality and quantification, ed. by Fritz Hamm and Erhard Hinrichs, 177-238. Dordrecht: Kluwer. 